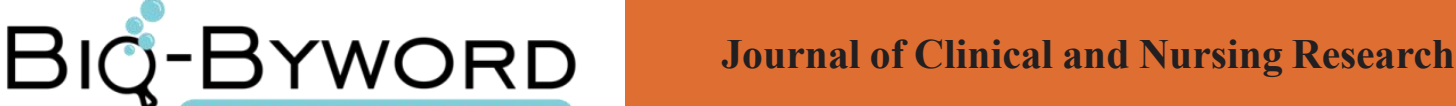

\section{The Effect of Operating Room Detail Management in Improving the Safety of Operating Room}

\author{
Yan Huirong
}

Tianmen Second People's Hospital Hubei Tianmen 431702

\section{ARTICLE INFO}

Article history:

Published online: $30^{\text {th }}$ Sept, 2017

Key words:

Operating room

Nursing safety

Detail management

\begin{abstract}
Objective: To study the method of improving the safety of the operating room, and to explore the application effect of detail management. Methods: The operating room of the hospital was used as a research object to study the effect of the operation room management in improving the safety of the operating room. In August 2016, the operation room was strengthened and the details of the operation room were col-lected. From June to August in 2016, the incidence of surgical accidents in the operating room ${ }^{[1]}$ was compared with that of patients who underwent surgery between August and October, and the satisfaction of patients and their families for surgical care was compared. Results: The incidence of accidents in the operating room was significantly lower than that in August, which was significantly different from that before strength-ening the detailed management $(\mathrm{P}<0.05)$. Conclusion: It is found that detailed management in the operating room has a positive effect on improving the safety of the operating room and can effectively reduce the accident rate in the operating room.
\end{abstract}

\section{Materials and methods}

\subsection{General information}

A total of 128 patients underwent surgery between June and August of 1816 were enrolled in this study. Among them, 64 patients from June to August were control group, 38 male patients and 26 female patients aged 18-67 years old, the average age was $(38.4 \pm 2.1)$ years old, the operation time was 42 to 265 minutes; between August and October 64 patients were observed group, 35 cases of male patients, female patients in 29 cases, age between 21 and 68 years of age, the mean age was $(37.1 \pm 1.9)$ years and the duration of surgery was 45 to 270 minutes. There was no significant difference in sex, age, and duration of operation between the two groups, and was not statistically significant $(\mathrm{P}>0.05)$.
1) To establish a nursing group in the operating room, the patient's basic information to do a detailed record, and according to the specific circumstances of the patient, the patient's specific information on the basis of the general care of the control group. 2) Preoperative details of the care is divided into two aspects of physical care and psychological care, first of all should be done before the patient's disinfection, the patient's best care, and inform the patient in the correct position and the operation of the precautions, and secondly, should give patients a great psychological support, give patients a few cases of surgery success stories, strengthen the patient's surgical confidence, and comfort patients during surgery care. 3) The operation should always accompany the patient in the side, if the patient is sober state, you can communicate with the patient, the appropriate dispersion of the patient's attention to ease the patient's attention to the patient's care Tension. At any time to observe the patient's physical function, including blood pressure heart rate $^{[3]}$, breathing and adverse reactions, try to avoid the 
occurrence of accidents, the use of medical equipment to do the timely cleaning and disinfection, so that the second use of surgery. Patients with long operation time, care workers should pay attention to the operation of patients with indoor insulation work, for traumatic orthopedic patients, the operation of low temperature symptoms may affect the patient's treatment. 4) After the patient's incision to do good disinfection care, and the patient's blood near the incision to clean up, inform the patient anesthesia disappeared the general time and postoperative attention, regular patients to stand up to prevent the patient after the condition of pressure sores, and the patient's family communication, to avoid family members in the nursing process has the wrong nursing action.

\subsection{Effective standard}

To explore whether there are accidents in the operation, including inadequate preparation of equipment, disinfection and isolation is not accurate, intraoperative coordination is not high; patients on the satisfaction of surgery is divided into three rating, that is satisfactory, satisfied, and not satisfied.

\subsection{Statistical analysis}

SPSS 16.0 statistical software for statistical analysis, measurement data (\%), with the $\mathrm{x}^{2}$ test, $\mathrm{P}<0.05$ for the data between the significant differences, with statistical significance.

\section{Results}

The probability of an accident in the operation group was significantly lower than that in the control group, and no significant medical accident was caused. The overall satisfaction of the patients was significantly higher than that of the control group. There was significant difference between the two groups $(\mathrm{P}<0.05)$;

Table 1 Two groups of patients in the accident occurred during surgery [n(\%)]

\begin{tabular}{ccccc}
\hline Group & Number & $\begin{array}{c}\text { Equipment } \\
\text { preparation is not } \\
\text { sufficient }\end{array}$ & $\begin{array}{c}\text { Disinfection isolation } \\
\text { is not accurate }\end{array}$ & $\begin{array}{c}\text { Surgical } \\
\text { coordination is not } \\
\text { high }\end{array}$ \\
\hline Control group & 64 & $3(4.68)$ & $6(9.37)$ & $4(6.25)$ \\
Observed group & 64 & $1(1.56)$ & $1(1.56)$ & $2(3.12)$ \\
x2 & & 5.494 & & \\
\hline
\end{tabular}

Note: In compared with control group, ${ }^{*} \mathrm{P}<0.05$

Table 2 Satisfaction rating between two groups of patients toward surgery [n(\%)]

\begin{tabular}{|c|c|c|c|c|}
\hline Group & Number & Satisfactory & Satisfied & Not satisfied \\
\hline Control group & 64 & $34(53.12)$ & $21(32.81)$ & $9(14.06)$ \\
\hline Observed group & 64 & $48(75)$ & $15(15.43)$ & $1(1.56)$ \\
\hline $\mathrm{x} 2$ & & & 6.942 & \\
\hline
\end{tabular}

Note: in compared with control group, ${ }^{*} \mathrm{P}<0.05$

\section{Discussion}

Detail management has a positive effect on the safety of care in the operating room. First, through the management of the patient's details can enhance the patient's surgical confidence, but also to strengthen the trust between the caregiver and the relationship between the establishment of care, nurses through the patients surgical health propaganda work to strengthen the patient's compliance with the operation, but also for doctors to create the most convenient surgical conditions; followed by the details of the operating room management should include the operating room temperature control, and the preparation of medical equipment. According to the patient's different surgical requirements in advance to prepare the patient's surgery to use the medical equipment, rigorous cleaning and disinfection to ensure that surgery will not bring infection to patients, etc.; Postoperative to strengthen the patient's details management to avoid postoperative concurrent disease. For a long time cannot get out of bed after the activities of patients, we should pay attention to reduce the risk of patients with pressure ulcer symptoms. We can do reasonable preventive measures and provide patients with a certain psychological care to avoid postoperative depression in patients' tendency.

\section{Conclusion}

In short, the details of the management are to further refine the nursing work, can effectively improve the operating room care security, in clinical care has a certain value to promote. 


\section{References}

[1] Zhang Jing. The effect of operating room detail nursing in improving the safety of the operating room nursing. Inner Mongolia Medical Journal, 2016, 9: $1147-1148$.
[2] Qian Lijuan. Surgical room details of nursing care in improving the safety of the operating room. Clinical Medicine literature, 2016, 58: 11600-11601.

[3] Chen Yaling. Surgical room details of nursing care in improving the safety of the operating room. China Health Standards Management, 2017, 6: 124-126. 